\title{
Foreign versus domestic factors as sources of macroeconomic fluctuations in Hong Kong
}

\author{
Hans Genberg \\ Graduate Institute of International Studies
}

\begin{abstract}
This paper uses a semi-structural vector autoregression approach to estimate the relative importance of domestic and foreign shocks as sources of macroeconomic fluctuations in Hong Kong since the adoption of the currency board. We find that external factors are clearly dominant in the medium- to long run. In view of the highly open nature of the Hong Kong economy and the linkages implied by the currency board arrangement, it is perhaps not unexpected. However, that these factors should account for fifty percent or more of unexpected fluctuations in real gdp and the gdp deflator at shorter horizons of one to two years is more surprising, and it is large in comparisons with other highly open small economies.
\end{abstract}

Even if external shocks are dominant sources of macroeconomic fluctuations, there remain significant short-term influences of domestic variables. For example, in the historical decomposition of the evolution of output growth and inflation we discovered a significant role for domestic factors in the recent recession. Their impact resembles very much those that would be generated by a conventional aggregate supply contraction. A challenge for future research is to identify empirically the exact sources of domestic shocks.

(C) The Authors.

All rights reserved. No part of this paper may be reproduced without the permission of the authors. 


\title{
Foreign versus domestic factors as sources of macroeconomic fluctuations in Hong Kong $^{1}$
}

\author{
Hans Genberg \\ Graduate Institute of International Studies \\ Geneva, Switzerland
}

\begin{abstract}
This paper uses a semi-structural vector autoregression approach to estimate the relative importance of domestic and foreign shocks as sources of macroeconomic fluctuations in Hong Kong since the adoption of the currency board. We find that external factors are clearly dominant in the medium- to long run. In view of the highly open nature of the Hong Kong economy and the linkages implied by the currency board arrangement, it is perhaps not unexpected. However, that these factors should account for fifty percent or more of unexpected fluctuations in real gdp and the gdp deflator at shorter horizons of one to two years is more surprising, and it is large in comparisons with other highly open small economies.

Even if external shocks are dominant sources of macroeconomic fluctuations, there remain significant short-term influences of domestic variables. For example, in the historical decomposition of the evolution of output growth and inflation we discovered a significant role for domestic factors in the recent recession. Their impact resembles very much those that would be generated by a conventional aggregate supply contraction. A challenge for future research is to identity empirically the exact sources of the domestic shocks.
\end{abstract}

\footnotetext{
${ }^{1}$ This paper is part of a project conducted by the author for the Hong Kong Institute for Monetary Research. Much of the research was carried out at the HKIMR when I was a Visiting Scholar there in August/September 2002. I am grateful to the HKIMR for providing a productive research environment and for help in obtaining data. Bill Branson, Paul DeGrauwe, Stefan Gerlach, and Andy Rose provided valuable comments at a presentation of an early version of the paper at the HKIMR. Laurent Pauwels of the Graduate Institute of International Studies provided efficient and able research assistance. All errors and omissions are my own responsibility.
} 


\section{Introduction.}

There can be little doubt that macroeconomic developments in Hong Kong are highly dependent on the evolution of international financial and goods markets. There is not much firm evidence, however, on the quantitative importance of these linkages. For example, it would be useful to know whether foreign influences count for fifty percent or ninety percent of business cycle fluctuations, and whether domestic factors therefore count for half or merely ten percent. The answer to this question is likely to depend on the horizon which one has in mind. External shocks are surely more important in the long run than in the short run, but by exactly how much?

Stating the problem somewhat differently, it would be interesting to quantify the importance of external and internal influences in specific periods such as the aftermath of the Asian Crisis and the almost simultaneous bursting of the local property price bubble and the more recent period of sluggish economic growth.

This paper provides quantitative assessment of these questions using a methodology developed first in Genberg, Salemi, and Swoboda(1987) for the purpose of testing whether a switch from a fixed to a floating exchange rate in Switzerland had any impact on the importance of external factors for Swiss macroeconomic fluctuations.

The next section of the paper explains the methodology which is based on the estimation and analysis of a vector autoregression (VAR) model for the Hong Kong economy. Identification of foreign shocks is achieved by exploiting a small-country assumption, according to which developments in Hong Kong do not have any impact on interest rates, prices and output in the rest of the world.

Section 3 describes the choice of domestic and foreign variables that will be included in the VAR, and section 4 explains the estimation methodology and reports the results. A concluding section restates the main findings and suggests avenues for future research.

\section{Methodology}

\subsection{From a structural model to a VAR representation.}

Consider an economy, which is small enough that it has no influence on economic conditions in the rest of the world. Let y denote a vector of domestic variables of interest, and $\mathrm{x}$ a vector of foreign variables relevant for the domestic economy. Then we can write structural models or this economy and of the rest of the world as equations (1) and (2) respectively.

$$
\begin{aligned}
& A y_{t}=A(L) y_{t-1}+B x_{t}+B(L) x_{t-1}+u_{t} \\
& C x_{t}=C(L) x_{t-1}+v_{t}
\end{aligned}
$$


where $A(L)=\sum_{i=0}^{l} A_{i} L^{i}, B(L)=\sum_{i=0}^{m} B_{i} L^{i}$, and $C(L)=\sum_{i=0}^{n} C_{i} L^{i}$

In these expressions the error terms $\mathrm{u}_{\mathrm{t}}$ and $\mathrm{v}_{\mathrm{t}}$ correspond to domestic and foreign structural shocks, respectively. These are the sources of macroeconomic fluctuations whereas the matrices $\mathrm{A}, \mathrm{A}(\mathrm{L}), \mathrm{B}, \mathrm{B}(\mathrm{L}), \mathrm{C}$, and $\mathrm{C}(\mathrm{L})$ correspond to the propagation mechanism of the shocks. What we are interested in determining is the relative importance of domestic and foreign shocks for the evolution of the variables contained in the vector $y$.

We can write (1) and (2) compactly as

$$
\left(\begin{array}{cc}
A & -B \\
0 & C
\end{array}\right)\left(\begin{array}{l}
y_{t} \\
x_{t}
\end{array}\right)=\left(\begin{array}{cc}
A(L) & B(L) \\
0 & C(L)
\end{array}\right)\left(\begin{array}{l}
y_{t-1} \\
x_{t-1}
\end{array}\right)+\left(\begin{array}{l}
u_{t} \\
v_{t}
\end{array}\right)
$$

from which we can derive the vector autoregression (VAR) representation as equation (4).

$$
\left(\begin{array}{l}
y_{t} \\
x_{t}
\end{array}\right)=\left(\begin{array}{cc}
D_{11}(L) & D_{12}(L) \\
0 & D_{22}(L)
\end{array}\right)\left(\begin{array}{l}
y_{t-1} \\
x_{t-1}
\end{array}\right)+\left(\begin{array}{l}
\varepsilon_{t} \\
\eta_{t}
\end{array}\right)
$$

where

$$
\begin{aligned}
& D_{11}(L)=A^{-1} A(L) \\
& D_{12}(L)=A^{-1}\left[B C^{-1} C(L)+B(L)\right] \\
& D_{22}(L)=C^{-1} C(L) \\
& \varepsilon_{t}=A^{-1} u_{t}+A^{-1} B C^{-1} v_{t} \\
& \eta_{t}=C^{-1} v_{t}
\end{aligned}
$$

Note that the assumption that the home economy does not influence the foreign variables implies (i) that the VAR representation is block triangular, and (ii) that the disturbances in the foreign block of the VAR only contain foreign structural shocks. On the other hand, unless there is no contemporaneous effect of the foreign on the domestic variables (i.e. unless $\mathrm{B} \equiv 0$ ) the disturbances in the domestic VAR block contain both domestic and foreign shocks. We shall exploit this property in the empirical work to distinguish between external and internal sources of macroeconomic fluctuations. ${ }^{2}$

Two types of complications have to be dealt with before we proceed: the implications of expectations variables in the structural equations, and the effects of

\footnotetext{
${ }^{2}$ This property has also been used in structural vector autoregression models (SVAR) where it has been helpful for solving the so-called price- and exchange-rate puzzles. See, for example, Cushman and Zha (1997).
} 
leaving out (in the empirical implementation) some relevant y or $\mathrm{x}$ variables. It turns out that neither of these will change the basic structure of the VAR representation, at least as far as our use of it is concerned. If expectations of future values of $y: s$ or $x: s$ belong in the structural model, then we can eliminate them by invoking an expectations generating mechanism where the expectations of future values are replaced by projections of current and past information. This means that expectations of future $\mathrm{y}$ :s will be functions of current and past values of $\mathrm{y}$ and $\mathrm{x}$, and that expectations of future values of $\mathrm{x}: \mathrm{s}$ will be functions of current and past values of $\mathrm{x}$. Hence, the structure of the VAR representation in equation (4) will remain the same, namely that the VAR residuals of the y variables will be functions (more complicated in this case) of the structural shocks to both domestic and foreign variables, whereas the VAR residuals in $\mathrm{x}$ equations will depend only on foreign shocks.

A similar argument can be made with respect to omitted variables. Suppose a domestic variable, $\mathrm{y}^{*}$, that is important for the propagation mechanism of the shocks is left out of the empirical model. In this case it is effectively included in the structural error term. In a larger model $\mathrm{y}^{*}$ would be a function of $\mathrm{y}$ and $\mathrm{x}$ and therefore of $\mathrm{u}$ ' and $\mathrm{v}^{\prime}$, the true structural errors in the equations for $\mathrm{y}$ and $\mathrm{x}$, as well as of $\mathrm{u}^{*}$, the structural error in the $\mathrm{y}^{*}$ equation that has been left out of the empirical model. Therefore, if we make the substitution, we notice that the 'structural' errors in the vector $\mathrm{u}$ are now functions of the true structural errors $\mathrm{u}^{\prime}, \mathrm{v}$ ', and $\mathrm{u}^{*}$. The structural errors in the equations for the foreign variables remain the same, however.

If some relevant foreign variable has been left out of the model, a similar argument implies that the structural errors in the $\mathrm{x}$ equations will be a linear function of the true errors in these equations and the error in the left-out equation. But the triangular structure of VAR would be preserved, including the property that VAR errors of the domestic variables will be a linear combination of both domestic and foreign shocks whereas the VAR errors corresponding to the foreign variables will be functions only of foreign shocks.

\subsection{A measure of the relative importance of domestic and foreign shocks.}

The moving average representation of $y_{t}$ and $x_{t}$ is given in (5)

$$
\left(\begin{array}{l}
y_{t} \\
x_{t}
\end{array}\right)=\left[I-\left(\begin{array}{cc}
D_{11}(L) L & D_{12}(L) L \\
0 & D_{22}(L) L
\end{array}\right)\right]^{-1}\left(\begin{array}{l}
\varepsilon_{t} \\
\eta_{t}
\end{array}\right)
$$

From this we can write the forecast error at horizon $h$ of each element of $y$ as a linear combination of the VAR errors to the equation for the domestic and foreign variables

$$
y_{i, t+h}-E_{t}\left(y_{i, t+h}\right)=\sum_{d=1}^{D} \sum_{l=1}^{h} \xi_{d, l} \cdot \varepsilon_{d, t+l}+\sum_{f=1}^{F} \sum_{l=1}^{h} \psi_{f, l} \cdot \eta_{f, t+l}
$$

The variance of the forecast error is

$$
V\left[y_{i, t+h}-E_{t}\left(y_{i, t+h}\right)\right]=\sum_{d=1}^{D} \sum_{l=1}^{h} \xi_{d, l}^{2} \cdot \sigma_{\varepsilon_{d}}^{2}+\sum_{f=1}^{F} \sum_{l=1}^{h} \psi_{f, l}^{2} \sigma_{\eta_{f}}^{2}+\sum_{d=1}^{D} \sum_{f=1}^{F} \sum_{l=1}^{h} \xi_{d, l} \psi_{f, l} \sigma_{\varepsilon_{d}, \eta_{f}}
$$


In view of the small-economy assumption that says that domestic shocks do not influence foreign variables, it must be that case that the contemporaneous correlation between the VAR errors $\varepsilon$ and $\eta$ must be due to the contemporaneous effect of $x$ on $y$ and not vice versa. Hence we can decompose the variance of the forecast errors into a domestic part which is the first term of the right hand side of (6) and a foreign part corresponding to the second and third terms. A convenient way to achieve an equivalent decomposition is to estimate the variance-covariance matrix of the VAR errors and render it diagonal by a Choleski decomposition in which the foreign variables come first in the ordering. This effectively ensures that the contemporaneous correlation between $\varepsilon$ and $\eta$ is due to the contemporaneous effect of $\mathrm{x}$ on $\mathrm{y}$. Then we get

$$
V\left[y_{i, t+h}-E_{t}\left(y_{i, t+h}\right)\right]=D_{i, h}+F_{i, h}
$$

where

$$
\begin{aligned}
& D_{i, h}=\sum_{d=1}^{D} \sum_{l=1}^{h} \xi_{d, l}^{2} \cdot \sigma_{\varepsilon_{d}}^{2} \\
& F_{i, h}=\sum_{f=1}^{F} \sum_{l=1}^{h} \psi_{f, l}^{2} \sigma_{\eta_{f}}^{2}+\sum_{d=1}^{D} \sum_{f=1}^{F} \sum_{l=1}^{h} \xi_{d, l} \psi_{f, l} \sigma_{\varepsilon_{d}, \eta_{f}}
\end{aligned}
$$

$\mathrm{D}_{\mathrm{i}, \mathrm{h}}\left(\mathrm{F}_{\mathrm{i}, \mathrm{h}}\right)$ stands for the domestic (foreign) contribution to the forecast error variance of $y_{i}$ at horizon $h$. The relative contribution of foreign variables to the forecast error of each domestic variable is therefore simply

$$
R E L_{i, h}^{F}=\frac{F_{i, h}}{D_{i, h}+F_{i, h}}
$$

To compute this we first estimate the VAR as shown in (4), i.e. imposing the block-triangular structure between domestic and foreign variables. We then orthogonalize the errors using the Choleski factorization of the variance-covariance matrix. Finally we calculate the forecast error variance decomposition and compute $\mathrm{REL}^{\mathrm{F}}$ for each of the domestic variables.

\section{The Choice of Domestic and Foreign Variables.}

The choice of variables to include in the VAR model is conditioned by two conflicting considerations. On the one hand one would like to include all variables that are relevant for the domestic macro-economy, and all foreign variables that have a significant effect on these variables. On the other hand one must limit the number of parameters to be estimated so as not to overfit the statistical model. The approach followed here will be to retain a minimum of three foreign variables representing international movements in prices, real output/demand, and interest rates, respectively. For the domestic economy the minimum is one variable representing real economic activity and one variable representing the evolution of some measure of the price level. In additional, variables that are either of intrinsic interest or thought to 
be important sources of shocks will be added to the extent that considerations of degrees of freedom permit. The robustness of the results will be checked by computing the $\mathrm{REL}^{\mathrm{F}}$ measure for several combinations of domestic and foreign variables.

Based on the above considerations, the following variables have been retained for the empirical analysis. The data series are obtained from the database maintained by the HKMA research department.

\subsection{Hong Kong variables.}

Real economic activity: Three alternative measures will be used, real GDP (RGDP), the unemployment rate (UNEMP), and a measure of the output gap (YGAP). The latter is obtained as the difference between the seasonally adjusted real gdp and a smoothed value of this variable. The smoothing was carried out in Eviews using the Hodrick-Prescott filter. ${ }^{3}$

Price level/inflation rate: The implicit GDP deflator $\left(\mathrm{P}^{\mathrm{GDP}}\right)$ and the consumer price index $\left(\mathrm{P}^{\mathrm{CPI}}\right)$.

Additional variables: Genberg and Pauwels (2003) argue that both the nominal wage rate (WAGE) and property prices $\left(\mathrm{P}^{\mathrm{PROP}}\right)$ are important for the evolution of inflation in Hong Kong. In addition, there is a general perception that the macroeconomic evolution in Hong Kong is influenced significantly by developments in the property market and by property prices in particular.

The local credit market could be one possible conduit for such an influence. For this reason, and more generally to investigate the importance of bank credit, the total value of loans extended by authorised Hong Kong financial institutions for use in Hong Kong (LOANS) will be used in the statistical model. Additional variables potentially measuring the independent influence of local credit market conditions would be the spread between the HKD rates on the Honk Kong interbank market and the USD-based Libor, ${ }^{4}$ or the spread between local lending rates and the local interbank market rate. These external and internal spreads will be referred to as EXTSPR and INTSPR respectively.

\subsection{Foreign variables.}

Interest rates: In view of the exchange rate link between the Hong Kong dollar and the US dollar, the obvious candidate to reflect external interest rate movements would be some representative US dollar interest rate. Possible candidates are the US Federal Funds rate (FEDF) reflecting relatively directly the monetary policy of the US Federal Reserve, an interbank rate such as the 3-month Libor rate (LIBOR3), or a 3-month

\footnotetext{
${ }^{3}$ The use of the Hodrick-Prescott to estimate the output gap in Hong Kong has been proposed in previous macroeconometric studies. See, in particular, Ha and Leung (2001) and Ha, Leung, and Shu (2002). See also Gerlach and Yiu (2002) for a comparison of the HP filter with an alternatives measure based on a Kalman filter technique.

${ }^{4}$ Such a spread could come about for three reasons: expectations of changes in the HKD/USD exchange rate, risk premia on HKD denominated assets, or temporary lack of liquidity in the local interbank market.
} 
Treasury bill rate (USTB3). ${ }^{5}$ In view of the high correlation between these variables, it is unlikely that the results would depend on which one is used.

Real economic activity: The HKMA data base contains a measure of 'world' GDP (WGDP) which is a weighted average of the real GDP:s of the seventeen most important trading partners for Hong Kong. This will be used as the principal measure of external real economic activity. If one considers the transmission of foreign real activity to take place via domestic (Hong Kong) exports, an alternative measure would be a weighted average of the total real imports of the main trading partners. This measure would differ from the external GDP measure to the extent that the GDP elasticity of imports is not the same for all trading partners.

Prices: External price influences on Hong Kong are felt directly either via import prices or export prices. Import prices have a direct influence on consumer prices through imported consumer goods, and an indirect effect to the extent imports are used as inputs for domestically produced goods. ${ }^{6}$ If Hong Kong were a complete price taker, a price index for imports $\left(\mathrm{P}^{\mathrm{IM}}\right)$ would capture these effects. ${ }^{7}$ However, the possibility that foreign exporters 'price to market' suggests that this measure may not be completely exogenous to economic developments in Hong Kong. ${ }^{8}$ Alternative measures of foreign price developments will therefore also be used. A weighed average of consumer prices in the main trading partners converted into HKD units (WCPI) would be one candidate, even though it includes non-traded goods in the foreign economies that have little direct impact on Hong Kong. To the extent that nominal exchange rate movements vis-à-vis trading partners constitute a major source of HKD prices of imports, a nominal effective exchange rate index (NEER) could capture the major movements import prices. ${ }^{9}$ Using both the 'world' consumer price index measured in foreign currencies (WCPI) and the nominal effective exchange would be another possibility.

If Hong Kong were a price taker on its export markets, an export price index would be a measure of foreign price influences. Due to the possibility that some Hong Kong exports are relatively specialised so that exporters have at least some pricing power, export prices will be treated as endogenous.

\section{Estimation results.}

\subsection{Data and estimation issues.}

All data series were obtained from the HKMA data base. Observations are quarterly and cover the time period 1984:1 -2002:2. All variables are measured as loglevels except interest rates that are percentages. The list of variables and their mnemonic are given in Table 4.1.

\footnotetext{
${ }^{5}$ Other maturities could also be included, but as noted in the text, all of the alternative interest rate variables are highly correlated.

${ }^{6}$ Note that the domestic retail price of imported goods usually contains a sizeable domestic component arising from distribution costs.

${ }^{7}$ The measure actually used is an index of the unit value of imports.

${ }^{8}$ I am grateful to Paul DeGrauwe for bringing up this possibility.

${ }^{9}$ Note that the NEER is determined completely outside of Hong Kong. Given the fixed HKD/USD parity, variations in the NEER for Hong Kong depend on exchange rates between Hong Kong's trading partners and the US dollar.
} 
Table 4.1. List of variables.

\begin{tabular}{ll}
\hline \multicolumn{1}{c}{ Foreign } & \\
\cline { 1 - 2 } USTB3 & US 3-month Treasury Bill rate \\
WGDP & World GDP \\
$\mathrm{P}^{\mathrm{IM}}$ & Unit value of imports into Hong Kong \\
WCPI & World CPI \\
Domestic & \\
\hline RGDP & Real GDP \\
$\mathrm{P}^{\mathrm{GDP}}$ & Implicit GDP deflator \\
$\mathrm{P}^{\mathrm{CPI}}$ & Consumer Price Index \\
LOAN & Total loans of financial institutions for use in Hong \\
& Kong. Measured in real terms using the GDP deflator \\
$\mathrm{P}^{\mathrm{PROP}}$ & Real property price index. Nominal index divided by \\
& GDP deflator \\
YGAP & $\begin{array}{l}\text { Deviation of real GDP from its long-run value defined } \\
\text { using a Hodrick-Prescott filter }\end{array}$ \\
UNEMP & Unemployment rate \\
WAGE & Nominal wage rate \\
\hline
\end{tabular}

Estimations were carried out using WinRATS 5.0. In unrestricted VAR systems each equation can be estimated efficiently with OLS. In our case the system is block-triangular, so some gain in efficiency can in principle be obtained using the SUR (Seemingly Unrelated Regression) technique. In robustness checks performed on a subset of the specifications reported below we found that the results for the variance decomposition were not sensitive to the estimation method, so the discussion in the following section is based on the OLS results.

The number of coefficients to estimate quickly becomes large in VAR systems as the number of included variables and the number of lagged values increase. For this reason we limited the size of the system to seven variables, three foreign and four domestic. In addition to a constant and three seasonal dummies, all equations included the same number of lags of the dependent and independent variables. To determine the length of the lags, two opposing considerations had to be considered. A longer lag structure is likely to capture the dynamic interactions more satisfactorily at the risk of overfitting the model when the number of observations is limited. A shorter lag 
structure on the other hand may fail to describe complex interrelations in the data. In addition, some practitioners recommend including lags covering more than one year in order to capture seasonal effects that remain even if deterministic seasonal factors have been included in the model. ${ }^{10}$ Attempting to use formal tests for the optimal lag length produced conflicting results. By definition, the Akaike information criterion penalizes additional lags less severely than the Schwarz criterion. When models with two up to six lags were compared, the former frequently pointed towards a relatively long lag structure (often six) whereas the latter indicated much shorter (as short as two in some specifications). Fortunately, the variance decompositions that emerged were not very sensitive to the different lag structures. For this reason, we followed the advice to include lags covering over one year to capture seasonal patters. With quarterly date this implied five lags. ${ }^{11}$

\subsection{Results.}

The base model included three foreign variables $\left\{\mathrm{USTB} 3, \mathrm{WGDP}, \mathrm{P}^{\mathrm{IM}}\right.$ \} measuring influences of interest rate fluctuations in world financial markets and quantity as well as price effects from goods markets. The four domestic variables $\left\{\right.$ RGDP, $\mathrm{P}^{\mathrm{GDP}}, \mathrm{P}^{\mathrm{PROP}}$, LOANS $\}$ were meant to capture the evolution of the goods market (both quantity and price), the credit market and the property market. The contribution of the foreign variables to the forecast error variance of each domestic variable is presented in Table 4.2, i.e. the numbers in the table represent the $\mathrm{REL}^{\mathrm{F}}$ measure defined in equation (7).

Table 4.2. Contribution of foreign variables to the forecast error variance of domestic variables. ${ }^{1}$ (Percent)

\begin{tabular}{|c|c|c|c|c|}
\hline Horizon & $\mathrm{P}^{\text {PROP }}$ & LOANS & RGDP & $\mathrm{P}^{\mathrm{GDP}}$ \\
\hline 1 & 12 & 21 & 17 & 17 \\
\hline 4 & 19 & 60 & 80 & 69 \\
\hline 8 & 54 & 80 & 92 & 73 \\
\hline 12 & 68 & 89 & 93 & 77 \\
\hline 24 & 80 & 96 & 96 & 85 \\
\hline
\end{tabular}

${ }^{1}$ Foreign variables: USTB3, $\mathrm{P}^{\mathrm{IM}}$, WGDP.

The first result to be highlighted is the extraordinary dependence on foreign variables of real GDP, the GDP deflator, and the volume of loans in Hong Kong after a period as short as two years. Over $70 \%$ of the forecast error variance of these variables can be ascribed to external influences. As a comparison, consider the results found for Switzerland in Genberg, Salemi and Swoboda (1987). At a horizon of 4 years, they reported values of $59 \%$ and $49 \%$ for the foreign influences on Swiss industrial production and CPI respectively. Even in a comparison with as small and open economy as Switzerland, macroeconomic variables in Hong Kong stand out as being substantially more dependent on foreign influences.

\footnotetext{
${ }^{10}$ Rats User Guide, p. 284.

${ }^{11}$ Results for specifications with other lag lengths can be obtained from the author on request.
} 
At a horizon of one year, the foreign influences are still dominant for output and the price level, but now domestic factors account for between 30 and $40 \%$. In the property market the importance of foreign influences is lower. Thus, over $80 \%$ of the forecast error variance of the property price index is accounted for by domestic shocks at a horizon of one year, a figure that stays as high as $46 \%$ after two years. Beyond three years, fluctuations of all domestic variables are dominated by foreign influences.

These results show that while domestic shocks do seem to have a certain important in the local property market, their influence on the overall macroeconomic situation, as represented by real GDP and the GDP deflator, is quite limited except in the very short run.

Having presented the results pertaining to the base model in some detail, we now discuss briefly how the results are affected when the list of included foreign and domestic variables is modified.

Tables 4.3 and 4.4 contain the results for systems where, respectively, the GDP deflator is replaced by the consumer price index and real GDP is replaced by the unemployment rate. While these changes have no impact on the variables represent the property and credit markets, the responses of prices and real economic activity are modified at short horizons. Thus, the domestic CPI has a larger domestic component than the GDP deflator, and the unemployment rate is significantly more influenced by domestic factors even at horizons of 3 years. It appears that the dynamics of adjustment in the domestic labor market is driven by local factors to a larger extent than overall GDP.

Table 4.3. Contribution of foreign variables to the forecast error variance of domestic variables. The base model but with $\mathrm{P}^{\mathrm{CPI}}$ replacing $\mathrm{P}^{\mathrm{GDP}}{ }^{1}$

(Percent)

\begin{tabular}{|c|c|c|c|c|}
\hline \multicolumn{5}{|c|}{ (Percent) } \\
\hline Horizon & $\mathrm{P}^{\mathrm{PROP}}$ & LOANS & RGDP & $\mathrm{P}^{\mathrm{CPI}}$ \\
\hline 1 & 17 & 21 & 11 & 12 \\
\hline 4 & 13 & 55 & 67 & 42 \\
\hline 8 & 49 & 75 & 78 & 70 \\
\hline 12 & 66 & 86 & 80 & 81 \\
\hline 24 & 84 & 94 & 82 & 90 \\
\hline
\end{tabular}

${ }^{1}$ Foreign variables: USTB3, $\mathrm{P}^{\mathrm{IM}}$, WGDP.

Table 4.4. Contribution of foreign variables to the forecast error variance of domestic variables. The base model but with UNEMP replacing RGDP. ${ }^{1}$

(Percent)

\begin{tabular}{|c|c|c|c|c|}
\hline Horizon & $\mathrm{P}^{\text {PROP }}$ & LOANS & UNEMP & $\mathrm{P}^{\text {GDP }}$ \\
\hline 1 & 15 & 22 & 1 & 17 \\
\hline 4 & 19 & 60 & 8 & 74 \\
\hline
\end{tabular}




\begin{tabular}{|c|c|c|c|c|}
\hline 8 & 54 & 76 & 37 & 70 \\
\hline 12 & 67 & 86 & 52 & 75 \\
\hline 24 & 80 & 95 & 61 & 85 \\
\hline
\end{tabular}

I Foreign variables: USTB3, $\mathrm{P}^{\mathrm{IM}}$, WGDP.

In order to pursue this line of reasoning, Table 4.5 refer to a specification were the domestic labor market is represented by two variables, the wage rate (replacing the loan variable) and the unemployment rate (replacing real GDP). The results are quite striking. The forecast error variances of the variables representing the local labor market and the local property market now dominated by domestic shocks at horizons up to two years, whereas the overall price level ( $\mathrm{P}^{\mathrm{GDP}}$ ) is still mostly influenced by foreign factors.

Table 4.5. Contribution of foreign variables to the forecast error variance of domestic variables. The base model but with WAGE replacing LOANS and UNEMP replacing RGDP. ${ }^{1}$

(Percent)

\begin{tabular}{|c|c|c|c|c|}
\hline Horizon & $\mathrm{P}^{\text {PROP }}$ & WAGE & UNEMP & $\mathrm{P}^{\text {GDP }}$ \\
\hline 1 & 15 & 3 & 3 & 17 \\
\hline 4 & 27 & 31 & 21 & 68 \\
\hline 8 & 65 & 67 & 51 & 71 \\
\hline 12 & 74 & 80 & 51 & 71 \\
\hline 24 & 82 & 87 & 61 & 72 \\
\hline
\end{tabular}

${ }^{1}$ Foreign variables: USTB3, $\mathrm{P}^{\mathrm{IM}}$, WGDP.

Additional variations were tried where interest rate spreads were used instead of the volume of loans to represent the domestic credit market. Two types of spreads were tried, that between the Libor and Hibor rates and that between the domestic loan rate and the external Libor rate. In each case the only noteworthy difference in the results was that the interest rate spreads contained a larger domestic component than the volume of loans. To save space and since no other variable was affected the results are not presented explicitly.

Two modifications in the list of foreign variables were explored, namely including a measure of the world CPI or the nominal effective exchange rate instead of the import price index to measure foreign price influences. As they yielded fundamentally the same results, only the effect of the former is presented here (see Table 4.6). We note that the short run importance of foreign factors for real GDP and the GDP deflator are now much smaller than in the base model. Evidently the world CPI does not capture foreign price influences on the Hong Kong economy as well as the import price index. This is consistent with the findings of Genberg and Pauwels (2003) in their study of the determinants of Hong Kong inflation.

Table 4.6. Contribution of foreign variables to the forecast error variance of domestic variables. The base model with WCPI replacing $\mathrm{P}^{\mathrm{IM}}$.

(Percent)

\begin{tabular}{|c|c|c|c|c|}
\hline Horizon & $\mathrm{P}^{\text {PROP }}$ & LOANS & RGDP & $\mathrm{P}^{\text {GDP }}$ \\
\hline 1 & 5 & 22 & 1 & 7 \\
\hline 4 & 19 & 61 & 31 & 41 \\
\hline
\end{tabular}




\begin{tabular}{|c|c|c|c|c|}
\hline 8 & 58 & 62 & 38 & 57 \\
\hline 12 & 66 & 61 & 54 & 67 \\
\hline 24 & 78 & 70 & 81 & 85 \\
\hline
\end{tabular}

Foreign variables: USTB3, WCPI, WGDP.

\subsection{Discussion.}

Taken together the results in this section point to a number of conclusions that merit highlighting. First, even by the standards of other small open economies, fluctuations in output and the general price level in Hong Kong are very dependent on the rest of the world. This is not only true in the medium run, but also at horizons as short as one to two years. Second, the labor market in Hong Kong, as represented here by the evolution of wages and the unemployment rate, responds predominantly to purely domestic shocks within a time horizon of two years. However, the dependence of these variables on local phenomena does not alter the conclusion that fluctuations in the overall price level are still dominated by external shocks at these frequencies. Apparently, while these results do not rule out the possibility that wage developments may be important it the propagation mechanism of external shocks, they suggest that the causal role of the labor market for domestic inflation is at best limited to the very short run. Third, of all the domestic variables investigated here, it is the property market that responds most strongly to domestic shocks, but whatever these shocks are, they do not seem to have a substantial persistent effect on the overall macroeconomic evolution in Hong Kong. In the concluding section of the paper I will use these conclusions to formulate hypotheses about structural macroeconomic relationships in Hong Kong that could be investigated in future empirical research.

\subsection{The importance of foreign shocks in the aftermath of the crisis in 1997 and in the recent downturn.}

In VARs it is possible to decompose the in-sample actual value of each variable into a part that is forecast on the basis the estimated dynamics of the system and a part that depends on shocks that have occurred during a particular time period. To be specific, equation (6) above can be rewritten as

$$
y_{i, t}-y_{i, t-h}=E_{t-h}\left(y_{i, t}-y_{i, t-h}\right)+\sum_{d=1}^{D} \sum_{l=1}^{h} \xi_{d, l} \cdot \varepsilon_{d, t-h+l}+\sum_{f=1}^{F} \sum_{l=1}^{h} \psi_{f, l} \cdot \eta_{f, t-h+l}
$$

The interpretation of this relationship is as follows. The actual change in the variable $y_{i}$ from time $\mathrm{t}$-h to time $\mathrm{t}$ can be decomposed into (i) a forecast or expected change (as of period t-h) which is the first term on the right hand side, (ii) the consequence of shocks to domestic variables in the time interval th to $t$ (the second term), and (iii) the consequence of shocks to foreign variables in the same time interval (the third term). The forecast, $E_{t-h}\left(y_{i, t}-y_{i, t-h}\right)$, represents the delayed effects implicit in the dynamics of the entire VAR system.

In this section this decomposition is used to illustrate the relative importance of predictable factors, foreign shocks, and domestic shocks for the evolution of output growth and inflation in period since the 1997 crisis in South-East Asia. We use the estimated values of the domestic and foreign shocks to decompose the path for these two variables from the last quarter of 1996 (t-h in the equation) until the end of the 
sample. In each case the paths of two counterfactual variables are calculated and presented in charts together with the actual values:

- 'No Shocks' which is simply $E_{t-h}\left(y_{i, t}\right)$ and

- 'Foreign shocks only' which is defined by $E_{t-h}\left(y_{i, t}\right)+\sum_{f=1}^{F} \sum_{l=1}^{h} \psi_{f, l} \cdot \eta_{f, t-h+l}$

Charts 4.1 and 4.2 are designed to shed some light on the reaction of growth and inflation in Hong Kong during the whole period since the crisis. The thick solid line in the graphs represents the actual values of growth and inflation respectively. ${ }^{12}$ The thin solid line represents the forecast based on data until 1996:4, which effectively means that it is based on the assumption that there will be no shocks from then onwards. The dashed line represents the forecast path plus the effects of the actual shocks to foreign variables from 1997:1 onwards. In other words, the difference between the thin solid line and the dashed line is the consequence of foreign shocks. Finally, the difference between the dashed line and the thick solid line represents the effect of domestic shocks.

The decomposition of the real growth rate illustrates the dominating role of foreign shocks for the Hong Kong economy. Virtually all of the unexpected contraction in output during 1998 and the subsequent recovery can be explained by external events. ${ }^{13}$ Domestic shocks exert only a slight negative influence which might be traced back to the bursting of the real estate bubble in the third quarter of 1997 . Most of the downturn starting in early 2000 can also be explained by external shocks, but to account for the sluggishness of the recovery in the beginning of 2002 it is necessary to bring in domestic factors. Foreign factors would have led to a real growth rate of about $4 \%$ in $2002: 2$, so the barely positive actual growth rate must be the result of negative domestic causes. ${ }^{14}$

The decomposition of the inflation rate shown in Chart 4.2 tells a similar story, although the role of domestic shocks is more pronounced in this case, especially in the early part of the period. The declining inflation rate during 1998 was partly predictable on the basis of developments until the beginning of 1997. Whereas foreign shocks during 1998 would have limited the decline the inflation rate somewhat, domestic factors pushed it down further. ${ }^{15}$ Again, the bursting of the property price bubble comes to mind as a likely explanation.

In the second part of the period shown in the graph the role of domestic and foreign factors are reversed. Unexpected external developments exert continuous deflationary pressures from 1999 until the middle of 2001. Domestic shocks are also deflationary until mid-2000, but after that they have generally expansionary effects.

When we bring together the deflationary effects on output growth of domestic shocks and their inflationary impact on inflation during 2001 and 2002, what emerges

\footnotetext{
${ }^{12}$ As explained before, the VAR system is estimated in levels. The charts are based on decompositions of the levels of real GDP and the GDP deflator, from which year over year growth rates have been calculated.

${ }^{13}$ See also Table 4.1 $\mathrm{a}$ in the Appendix which highlights the decomposition of forecast errors rather than the actual value of the variable.

${ }^{14}$ The non-structural nature of the VAR model in this paper does not allow us to identify the specific domestic cause(s) of the lack of growth. We hope to address this issue in future research.

${ }^{15}$ See Table $4.2 \mathrm{a}$ in the appendix for further details.
} 
is an explanation of recent developments that emphasizes adverse aggregate supply shocks in the economy. As already noted, the non-structural nature of the VAR model estimated here does not permit us to be more specific about the exact sources of these supply shocks. This remains a challenge for future research.

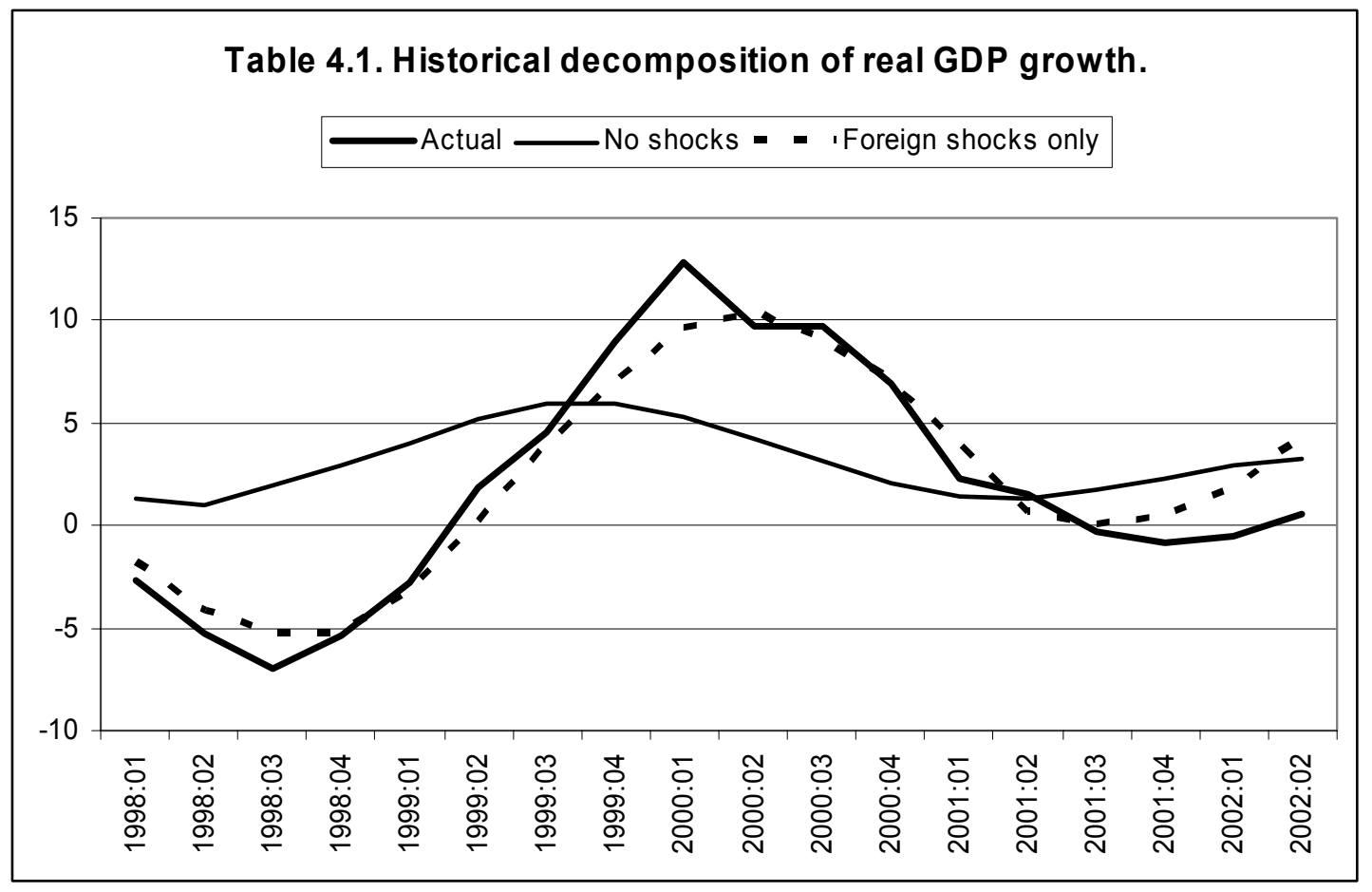




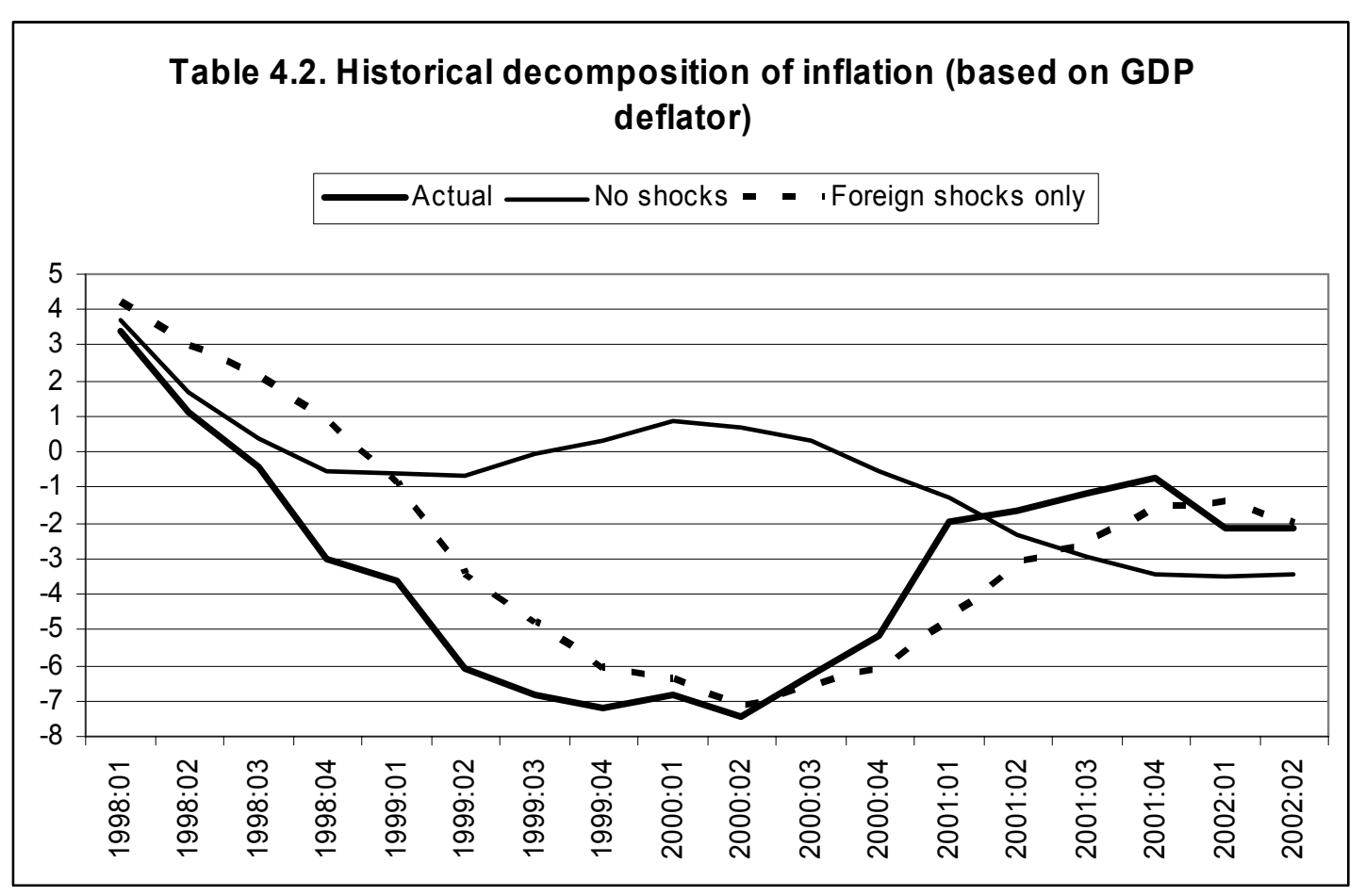

\section{General conclusions.}

The empirical methodology used in this paper has allowed us to establish a number of significant conclusions and to raise questions for future research. We have quantified the importance of foreign shocks for the local economy. In view of the highly open nature of the Hong Kong economy and the linkages implied by the currency board arrangement, it is not really surprising that macroeconomic developments should be dominated by external factors in the medium- to long run. That these factors should account for fifty percent or more of unexpected fluctuations in real gdp and the gdp deflator at horizons of one to two years is more surprising. In comparisons with Switzerland the external dependency of Hong Kong is very large. It would be interesting to conduct a similar study for Singapore, an economy which in term of openness resembles Hong Kong more than Switzerland does, to determine whether differences in exchange rate regime matters for the importance of domestic versus external shocks. ${ }^{16}$

Even if external shocks are dominant sources of macroeconomic fluctuations, there remain significant short-term influences of domestic variables. For example, in the historical decomposition of the evolution of output growth and inflation we discovered a significant role for domestic factors in the recent recession. Their impact resembles very much those that would be generated by a conventional aggregate supply contraction. A challenge for future research is to identity empirically the exact sources of the domestic shocks. Our results suggest that developments in the local

\footnotetext{
${ }^{16}$ Alternatively one could compare the sources of macroeconomic fluctuations in the Hong Kong economy before and after the adoption of the currency board in 1983. This is an approach followed by Kwan and Lui (1996), but they do not explicitly consider the influence of foreign shocks as we have done here.
} 
labor market may be important. At certain times it also appears that unexpected shocks in the property and credit markets may have had influences on overall growth and inflation. 


\section{References.}

Cushman, David, and Tao Zha (1997). "Identifying monetary policy in a small open economy under flexible exchange rates", Journal of Monetary Economics, Volume 39, pp. 433-448.

Genberg, Hans and Laurent Pauwels (2003). " "Inflation in Hong Kong, SAR - In Search of a Transmission Mechanism" Hong Kong Institute for Monetary Reserarch Working paper. WP No.1/2003.

Genberg, Hans, Michael K. Salemi, and Alexander Swoboda (1987). "The relative importance of foreign and domestic distrubances for aggregate fluctuations in the open economy, Switzerland 1964-81", Journal of Monetary Economics, Volume 19, pp. 45-67.

Gerlach, Stefan and Matthew S. Yiu. "Unobservable-Component Estimates of Output Gaps in Five Asian Economies". Hong Kong Institute for Monetary Reserarch Working paper. WP No.5/2002.

Ha, Jiming and Cynthia Leung, "Estimating Hong Kong's Output Gap and Its Impact on Inflation”, Research Memorandum, HKMA November 2001.

Ha, Jiming, Cynthia Leung and Chang Shu, "A Small Macroeconomic Model of Hong Kong”, Research Memorandum, HKMA, June 2002.

Kwan, Yum K. and Francis T. Lui, "Hong Kong's Currency Board and Changing Monetary Regimes", Working Paper No. 7523, National Bureau of Economic Research, August 1996. 
Appendix. Decomposition of the forecast errors of real growth and inflation.

The decompositions in Charts 4.1a and 4.2a below are based on

$y_{i, t}-E_{t-h}\left(y_{i, t}\right)=\sum_{d=1}^{D} \sum_{l=1}^{h} \xi_{d, l} \cdot \varepsilon_{d, t-h+l}+\sum_{f=1}^{F} \sum_{l=1}^{h} \psi_{f, l} \cdot \eta_{f, t-h+l}$

The bold solid line depicts the term of the left hand side of (A1). The thin solid line captures the effects of domestic shocks (the first term on the r.h.s.) and the dashed line the effects of foreign shocks (the second term on the r.h.s.).

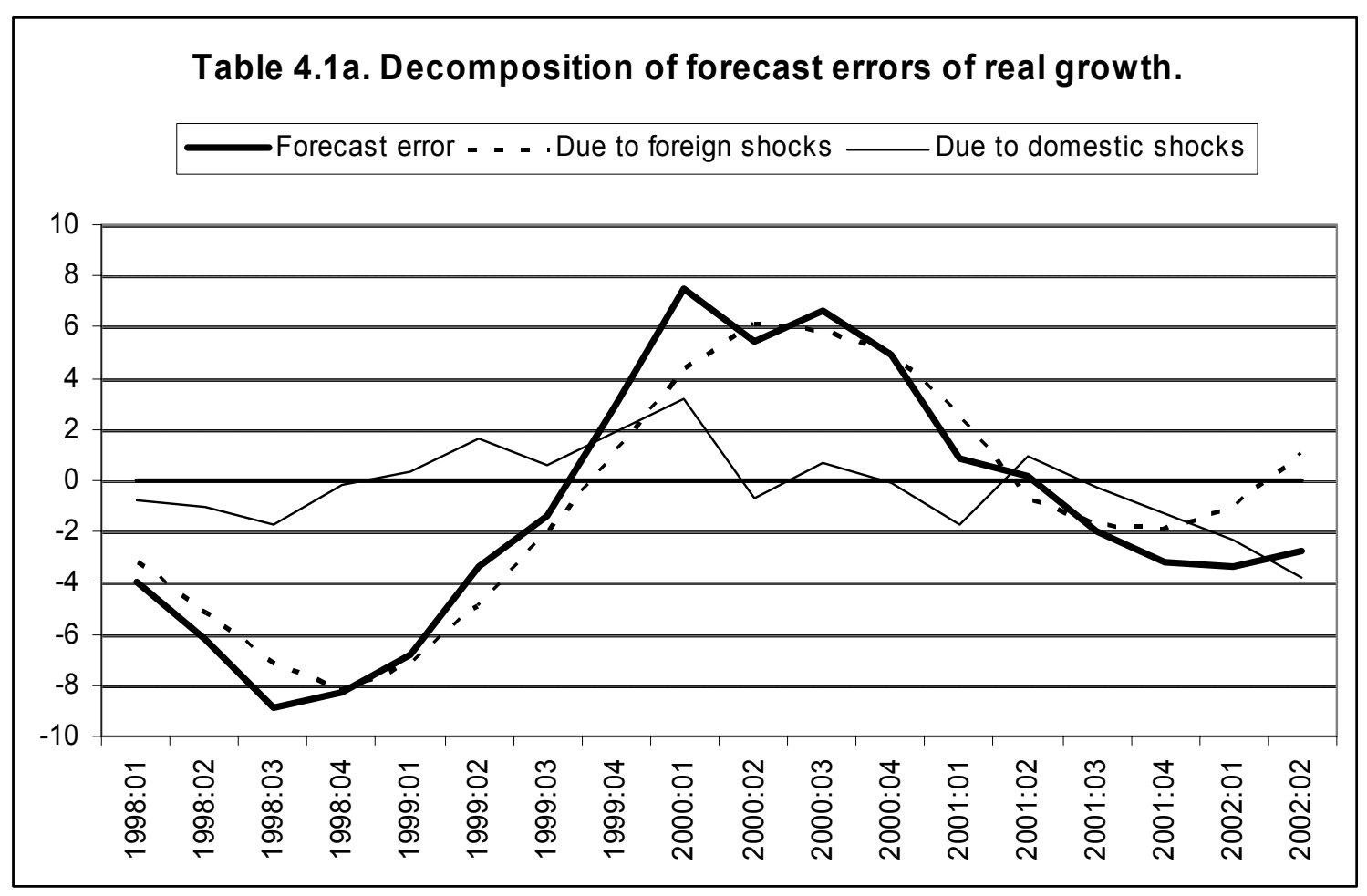

${ }^{17}$ See the discussion of equation (6) in the main text for an explanation of the symbols. 


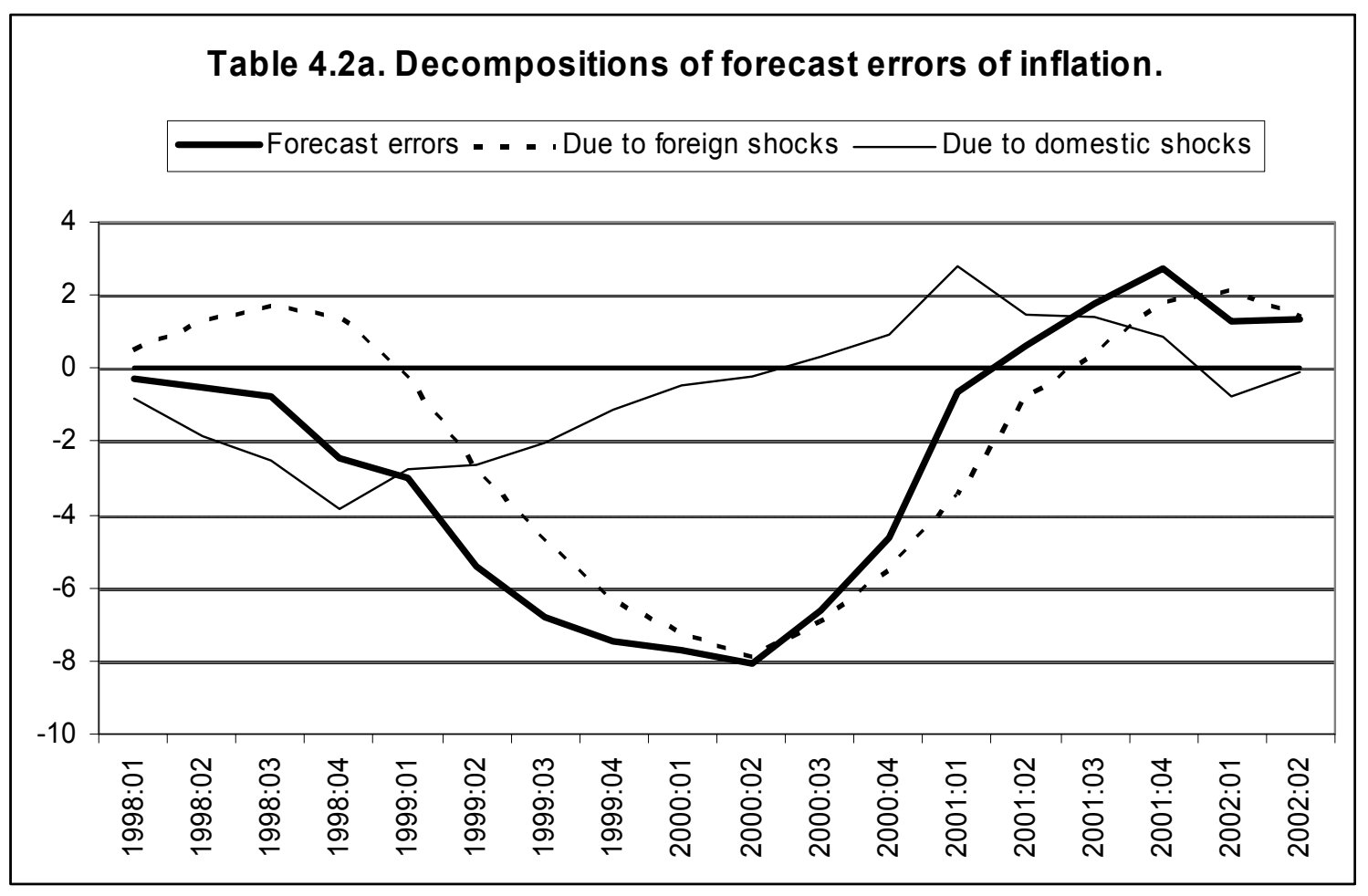

